Supplement of Biogeosciences, 16, 3069-3093, 2019

https://doi.org/10.5194/bg-16-3069-2019-supplement

(C) Author(s) 2019. This work is distributed under

the Creative Commons Attribution 4.0 License.

(c) (1)

Supplement of

\title{
Estimating global gross primary productivity using chlorophyll fluorescence and a data assimilation system with the BETHY-SCOPE model
}

Alexander J. Norton et al.

Correspondence to: Peter J. Rayner (prayner@unimelb.edu.au)

The copyright of individual parts of the supplement might differ from the CC BY 4.0 License. 
Observational Uncertainties 
OCO-2 SIF Uncertainty for January 2015

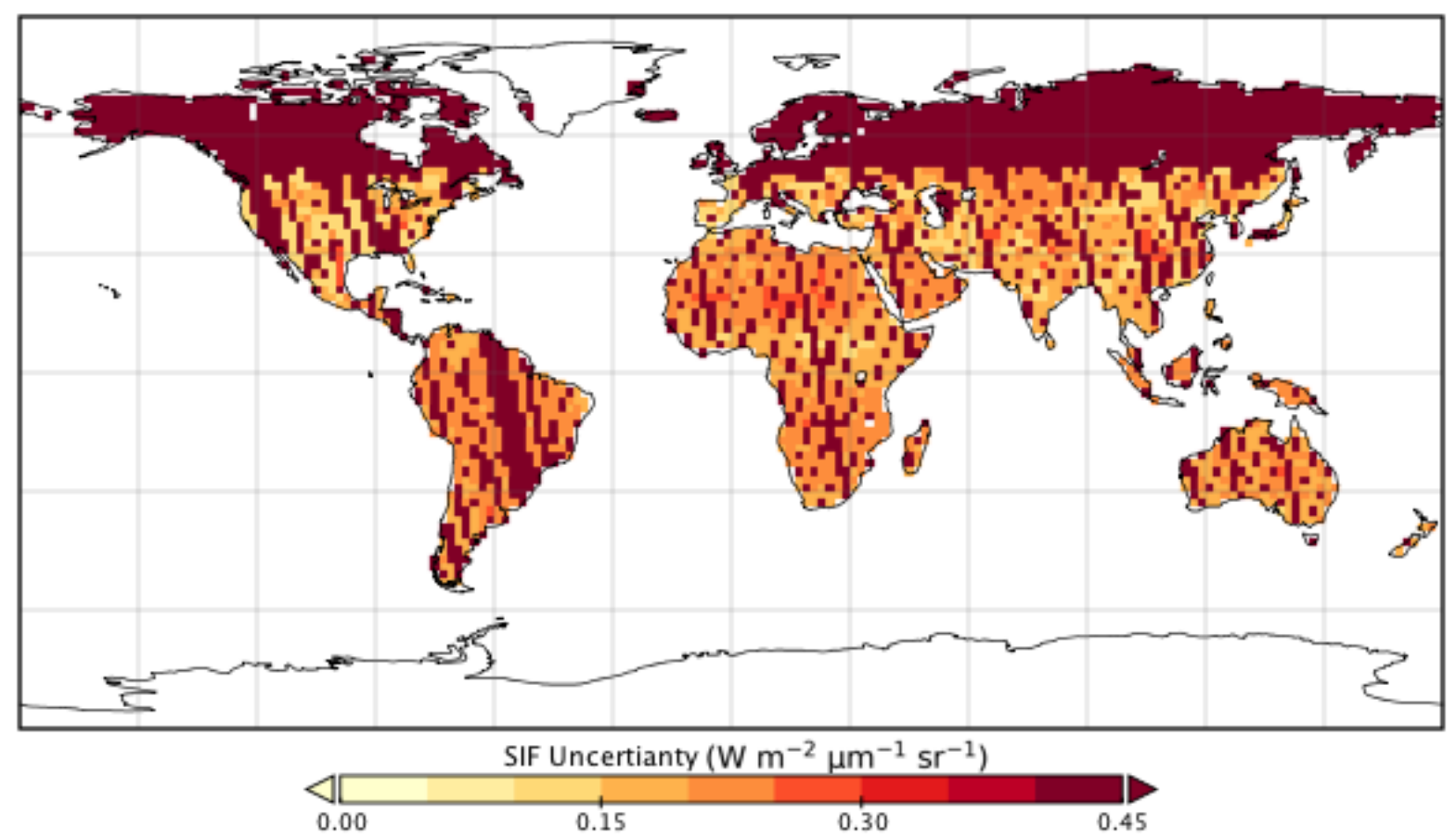

Figure S1. One standard deviation uncertainty in OCO-2 SIF for January 2015. Dark red grid cells have no observations. 
OCO-2 SIF Uncertainty for July 2015
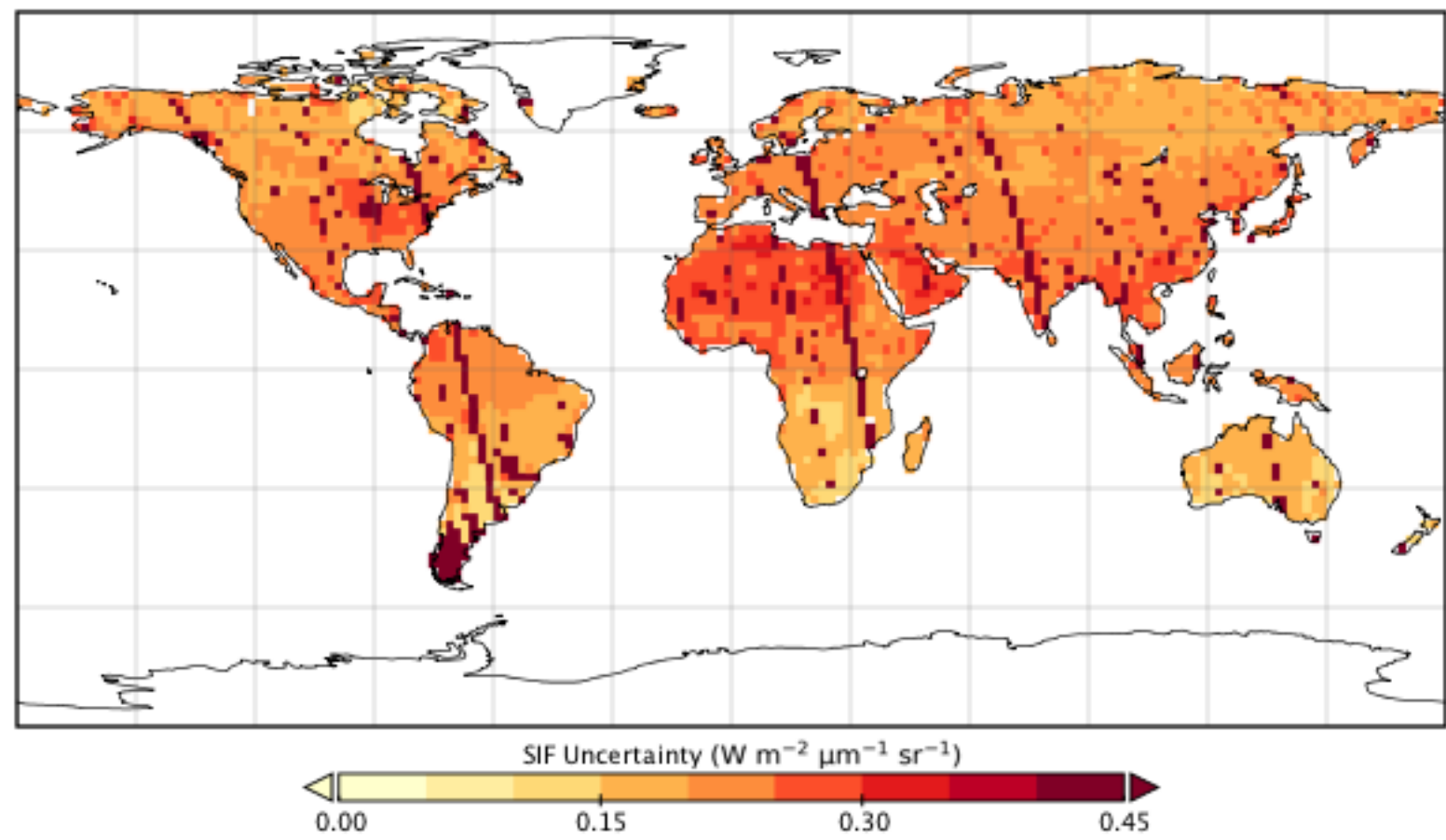

Figure S2. One standard deviation uncertainty in OCO-2 SIF for July 2015. Dark red grid cells have no observations. 
Model-Observed Fit 

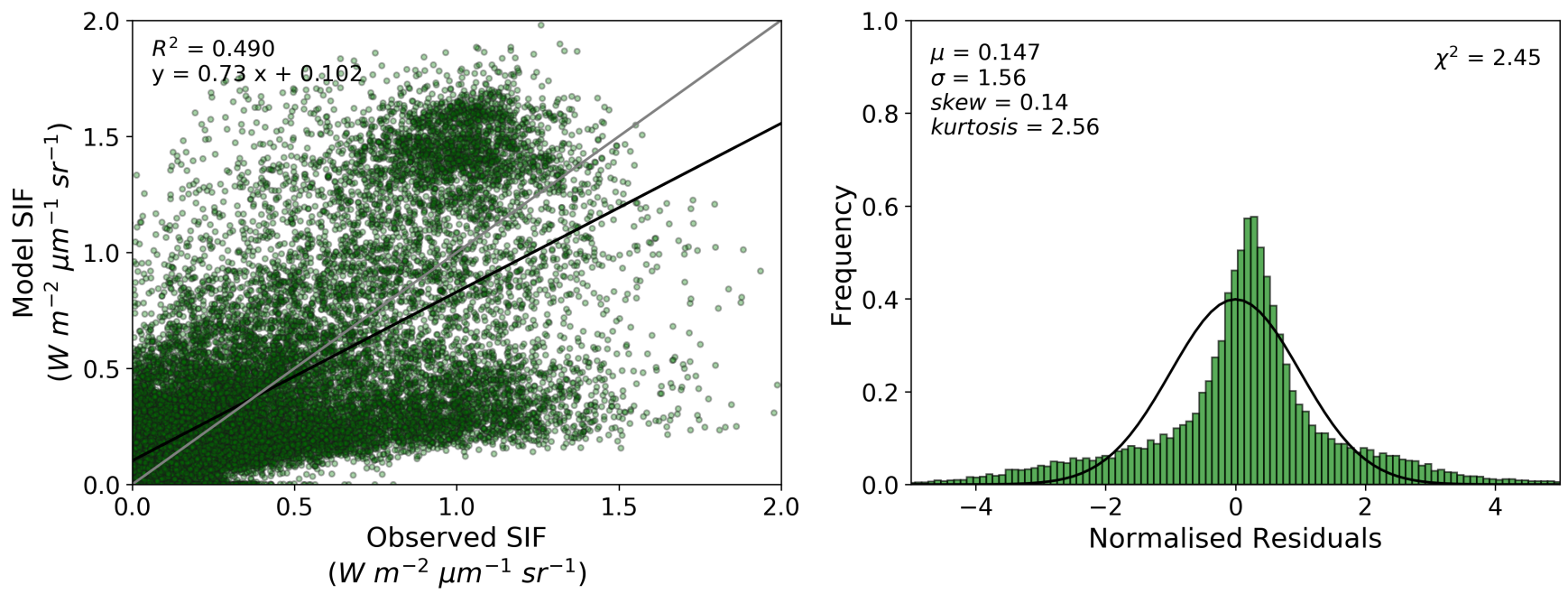

Figure S3. Prior model-observed fit and normalized residuals (modelled minus observed SIF divided by observational uncertainty) over the calibration period ( $\mathrm{SIF}_{\text {prior }}$ ). 

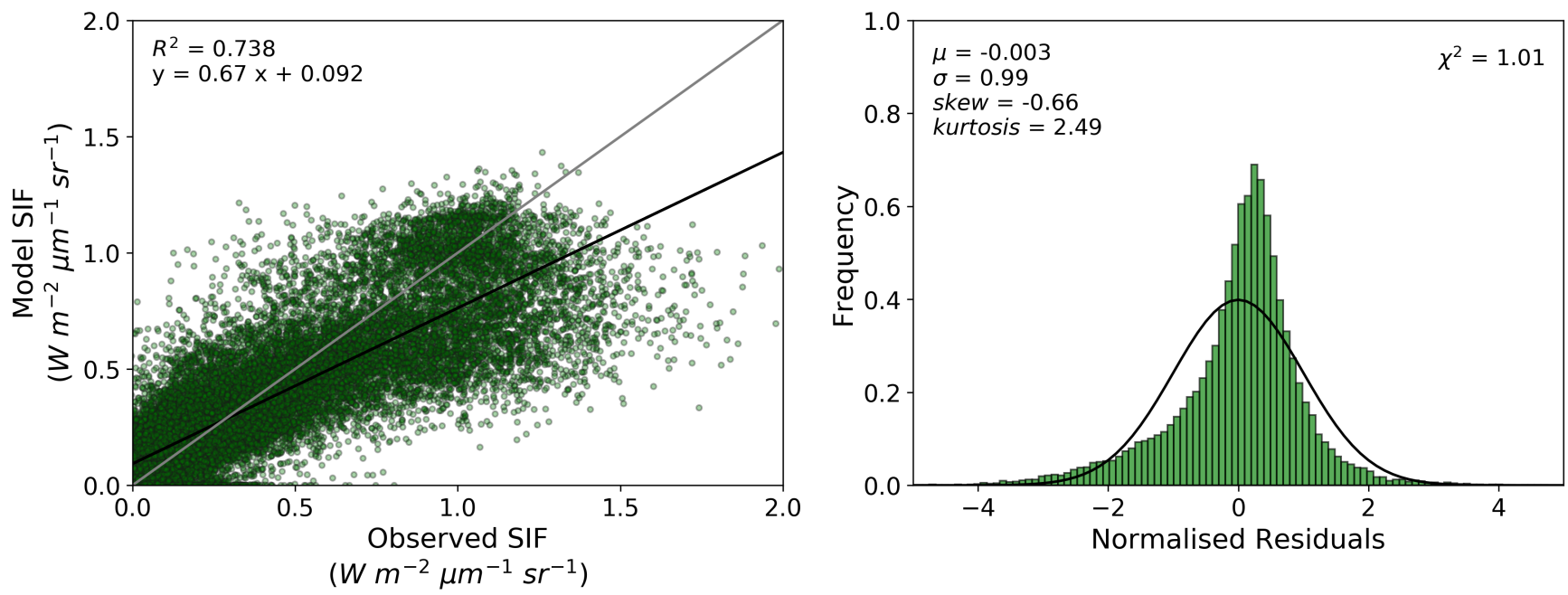

Figure S4. Posterior model-observed fit and normalized residuals (modelled minus observed SIF divided by observational uncertainty) over the calibration period $\left(\mathrm{SIF}_{\text {post }}\right)$. 

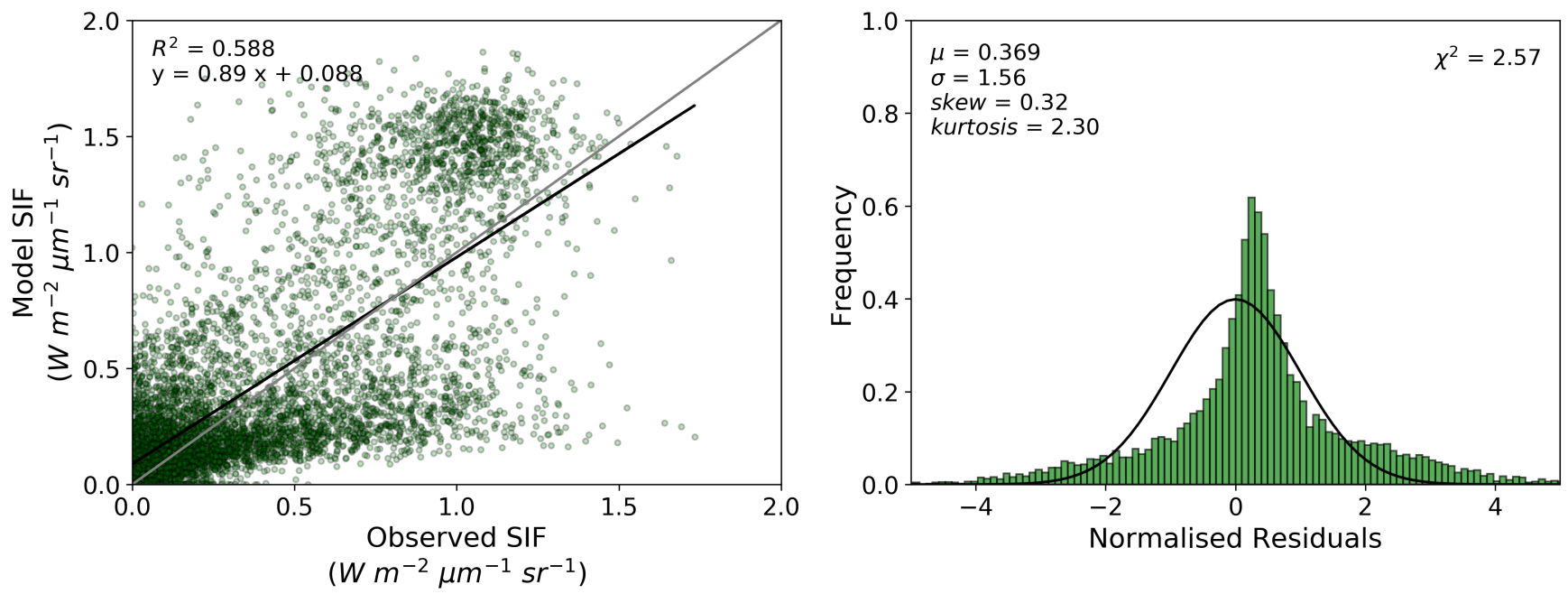

Figure S5. Prior model-observed fit and normalized residuals (modelled minus observed SIF divided by observational uncertainty) over the validation period. 

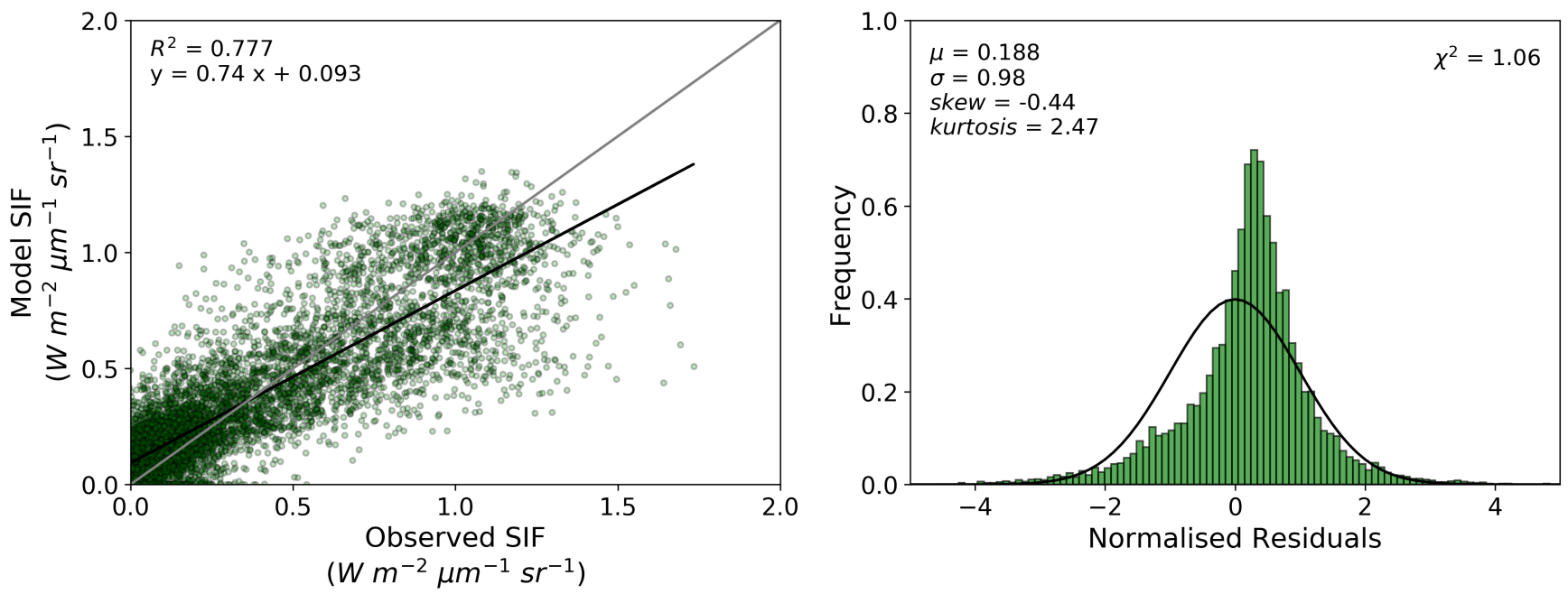

Figure S6. Posterior model-observed fit and normalized residuals (modelled minus observed SIF divided by observational uncertainty) over the validation period. 

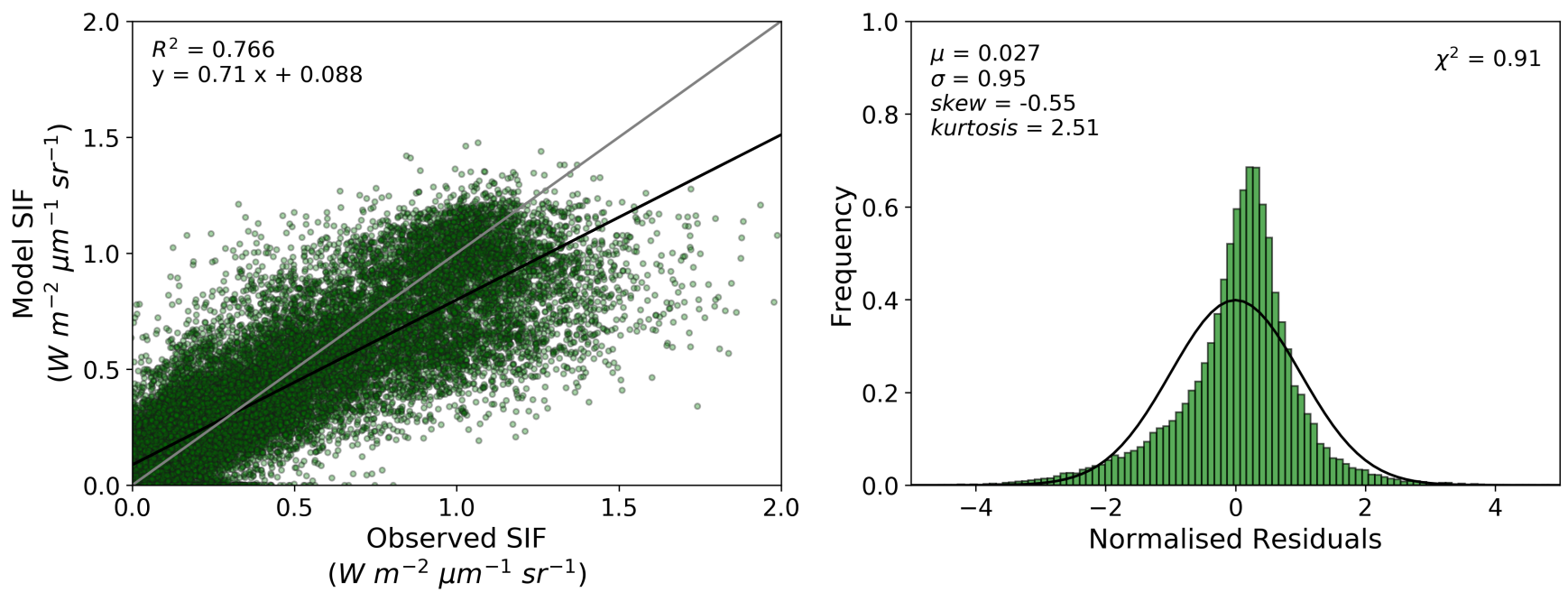

Figure S7. Posterior model-observed fit and normalized residuals (modelled minus observed SIF divided by observational uncertainty) for the sensitivity case with seasonally-adjusted parameters over the calibration period. 
Model-Observed Mismatch 


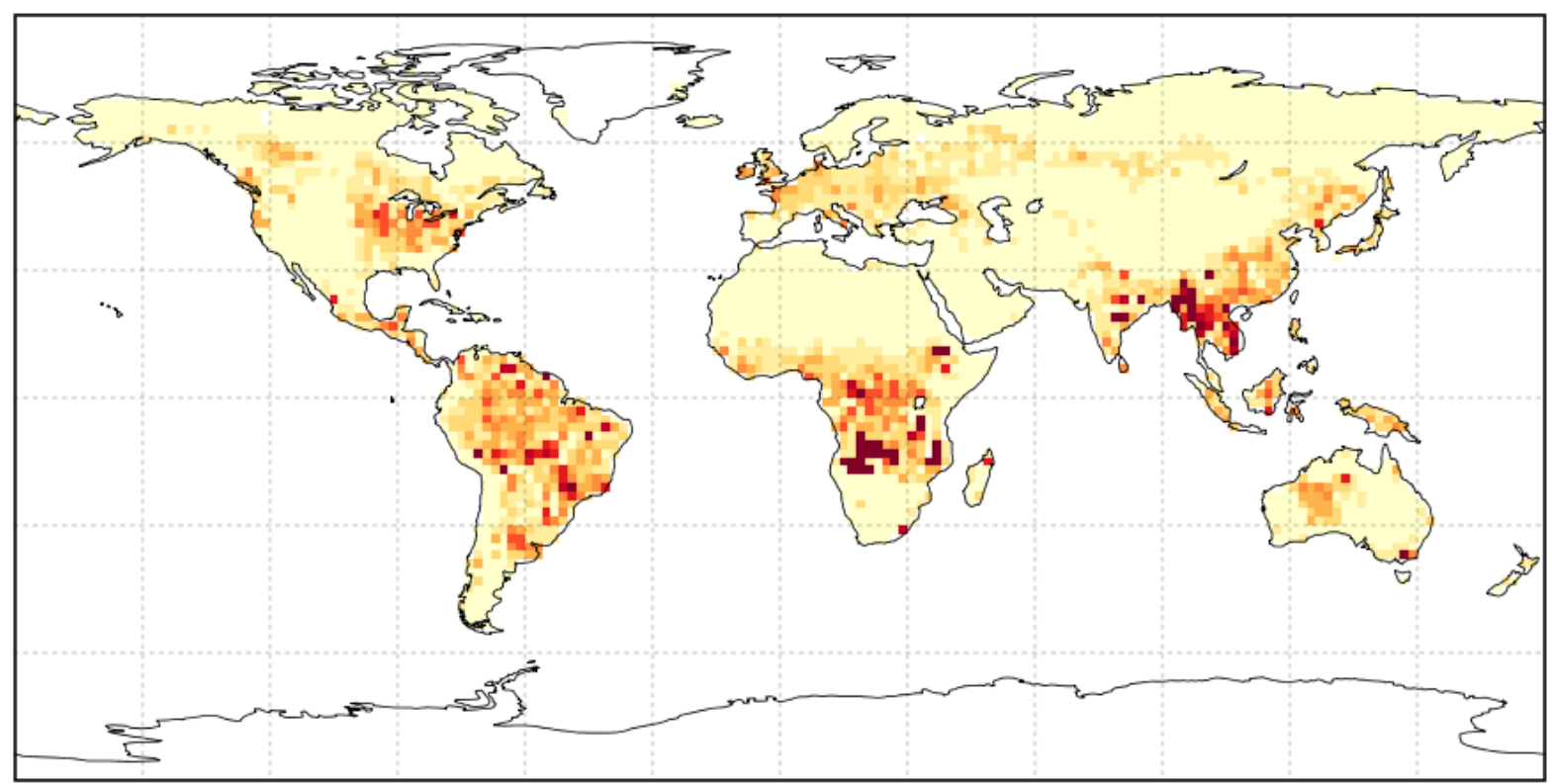

Prior Mismatch (unitless)

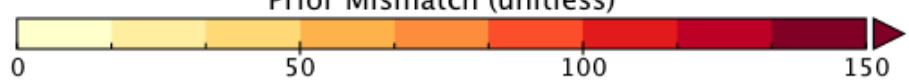

Figure S8. Annual total mismatch between the observed SIF and prior model SIF ( $\left.\mathrm{SIF}_{\text {prior }}\right)$. 


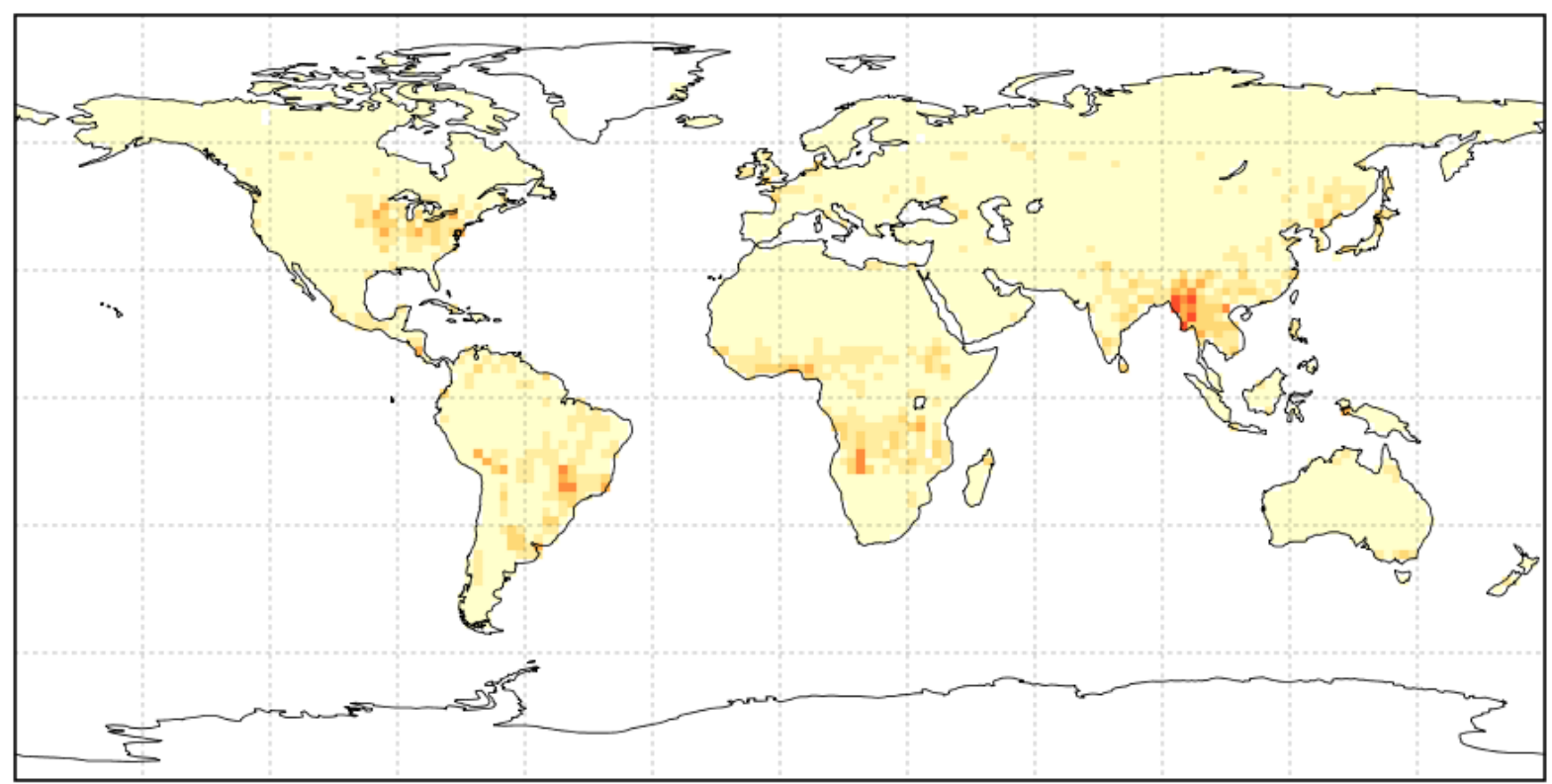

Posterior Mismatch (unitless)

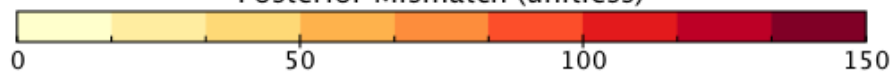

Figure S9. Annual total mismatch between the observed SIF and posterior model SIF ( $\left.\mathrm{SIF}_{\text {post }}\right)$. 

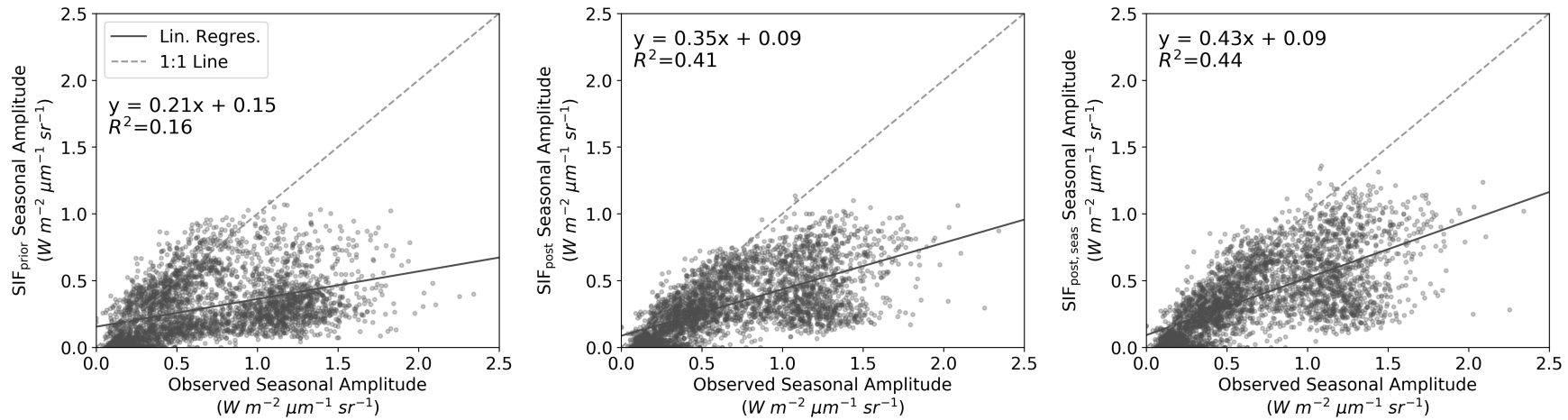

Figure S10. Model versus observed seasonal amplitude of SIF for the prior model (left), SIF-optimized model (middle), and SIF-optimized model with seasonally varying $C_{a b}$ and $V_{c \max }$ parameters (right). Shown on each plot is a 1:1 line (grey) and linear regression line (blue) with the associated equation. Also shown is the mean ratio between the model and observed seasonal amplitude. 
Regional Model-Observed Differences 

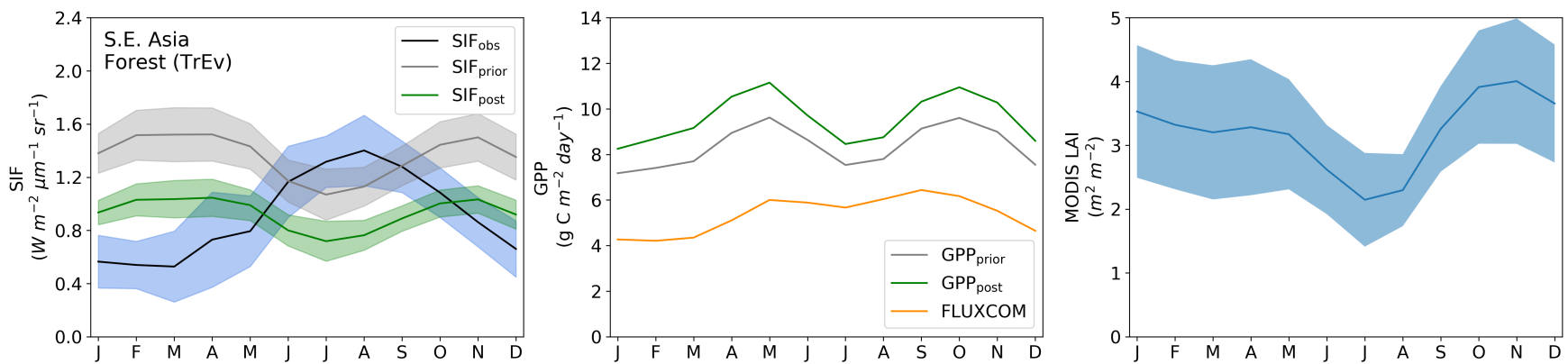

Figure S11. Regional patterns of SIF (left), GPP (center) and LAI (right) over mainland south-east Asia only for model grid cells with TrEv as the dominant PFT (see Fig. S12). The shading represents one sigma spread of data points in the selected region and month. 


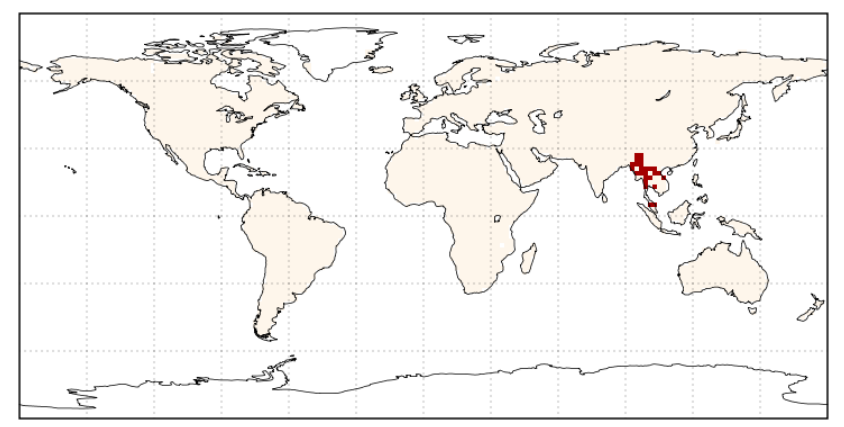

Figure S12. Model grid points selected for the regional analysis of mainland south-east Asia tropical forest. 

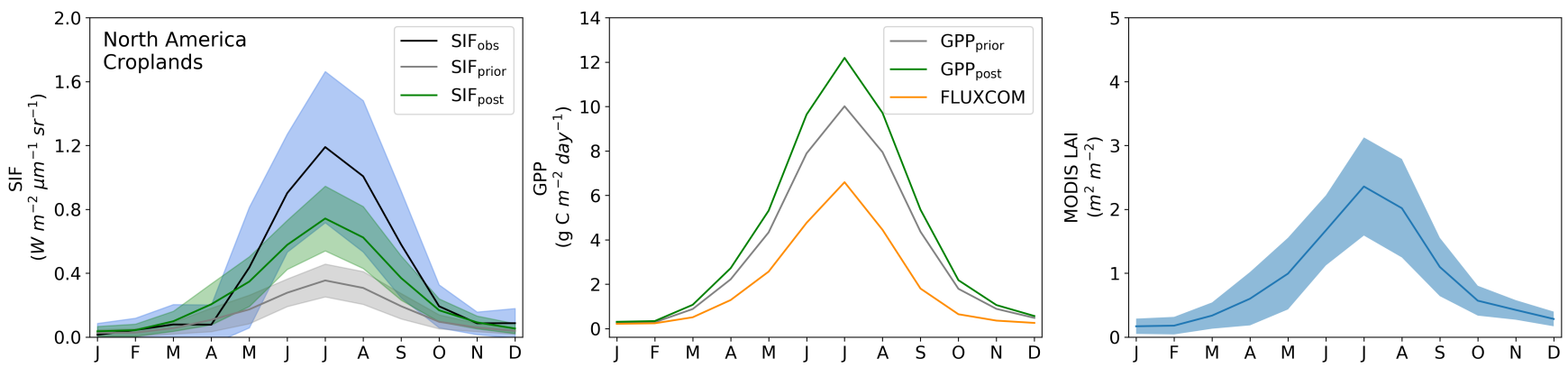

Figure S13. Regional patterns of SIF (left), GPP (center) and LAI (right) over North America croplands only for model grid cells with Crop as the dominant PFT (see Fig. S14). The shading represents one sigma spread of data points in the selected region and month. 


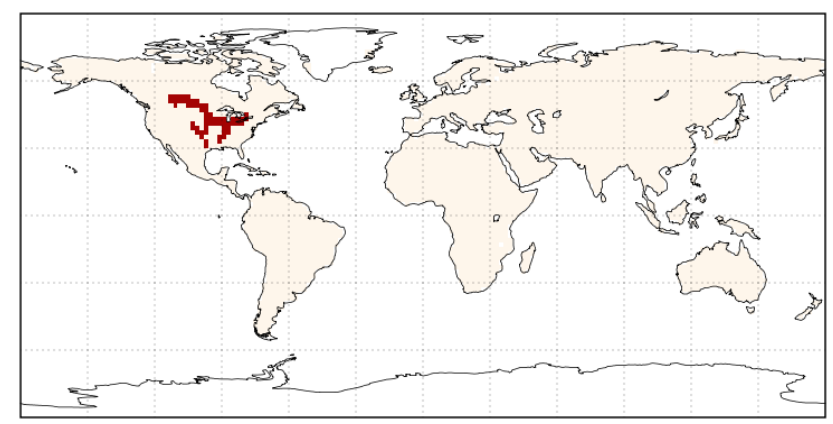

Figure S14. Model grid points selected for the regional analysis of North American croplands. 

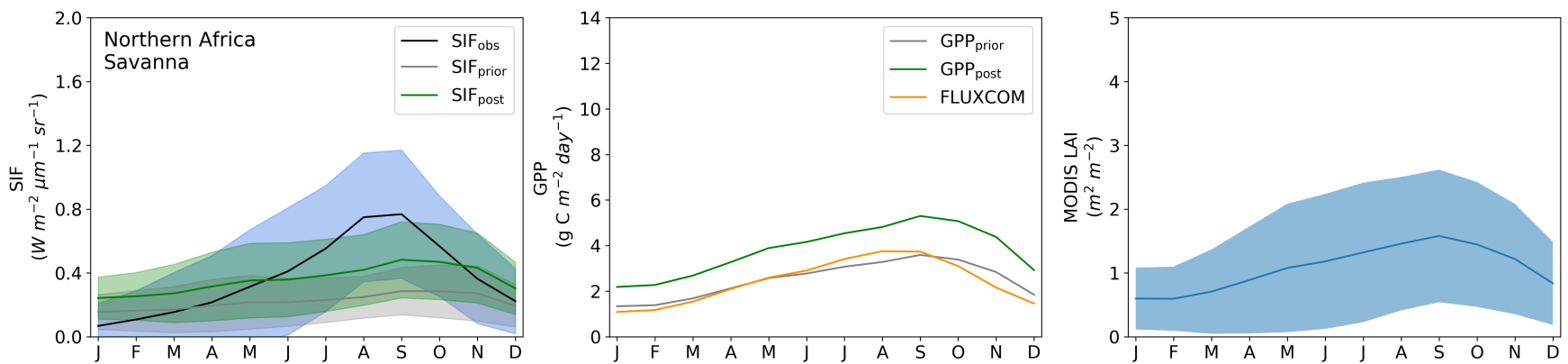

Figure S15. Regional patterns of SIF (left), GPP (center) and LAI (right) over north Africa savanna only for model grid cells with C4 grass as the dominant PFT (see Fig. S16). The shading represents one sigma spread of data points in the selected region and month. 


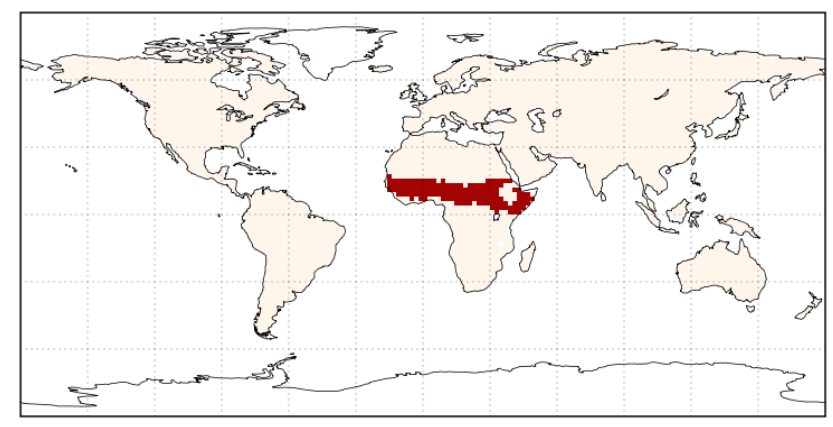

Figure S16. Model grid points selected for the regional analysis of north African savanna. 
Seasonal Adjustment of Parameters 
This equation determines the seasonal adjustment made to $V_{c \max }$ and $C_{a b}$ parameters for the sensitivity test in Section 3.1.3. The posterior parameter value is denoted by $x_{p o s t}$ and the seasonally adjusted parameter value is denoted by $x_{a d j u s t e d}$. Note that for highly seasonal PFTs including deciduous trees and shrubs, C3 and C4 grasses, and crops, the amplitude factor (f) is set to $50 \%$ of the mean ( $\mathrm{f}=0.5)$, while for all other PFTs the amplitude is set to $10 \%(\mathrm{f}=0.1)$. The DOY is the day of the year, 5 between 1 and 365 .

$x_{\text {adjusted }}(D O Y)=x_{\text {post }}+f x_{\text {post }} \sin (2 \pi / 365(D O Y-81))$

$x_{\text {adjusted }}(D O Y)=x_{\text {post }}+f x_{\text {post }} \sin (2 \pi / 365(D O Y-264))$ 
Spatiotemporal Patterns of GPP, SIF, $V_{c m a x}$ and $C_{a b}$ 

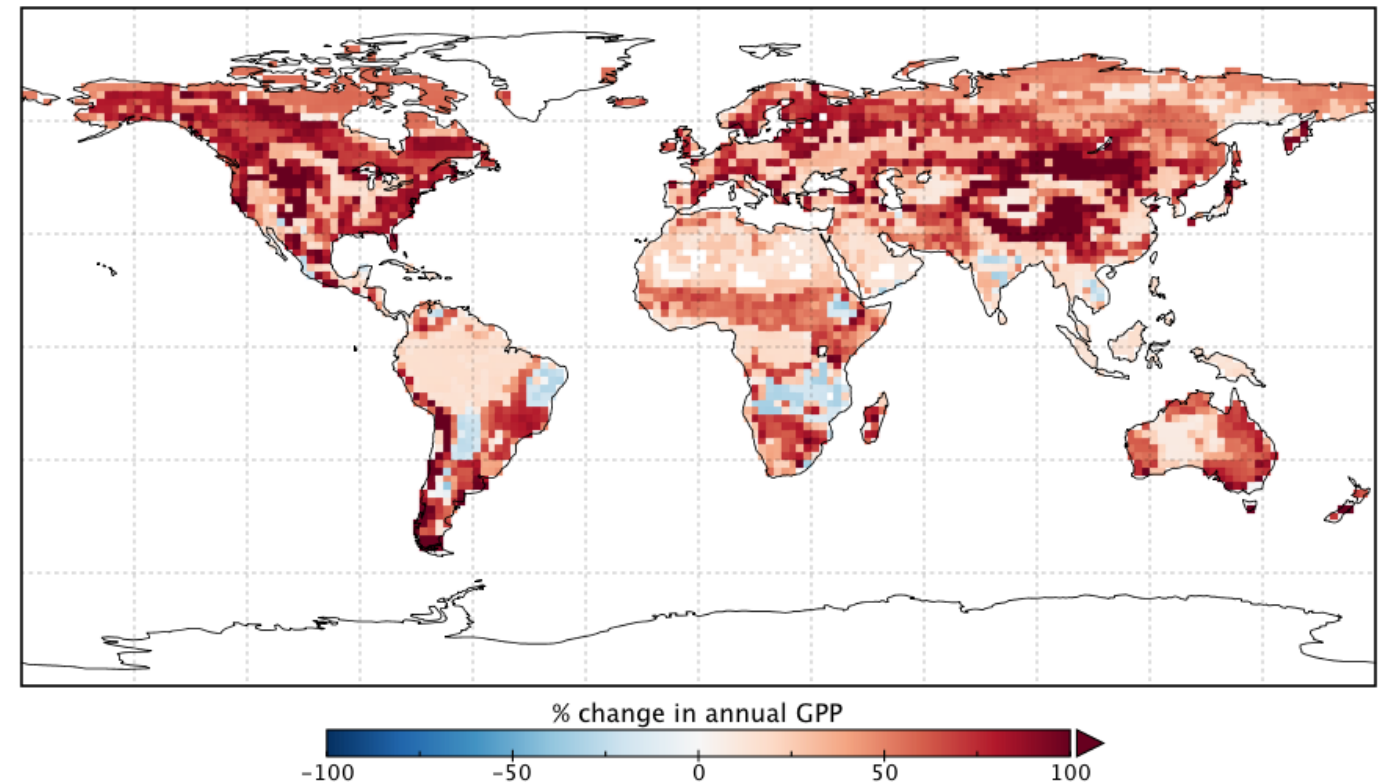

Figure S17. Percentage change in annual mean GPP rate for 2015 following optimization with SIF relative to GPP ${ }_{\text {prior }}$. 


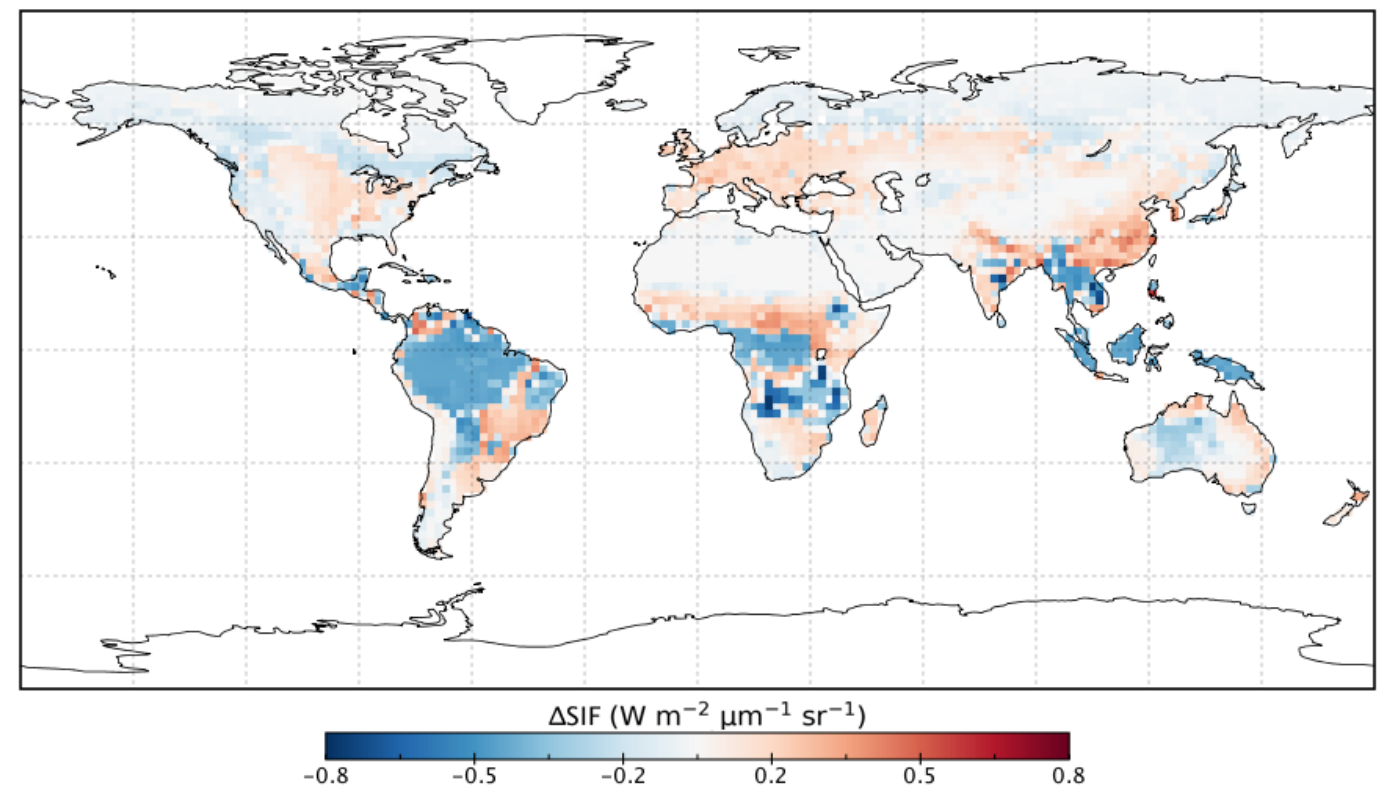

Figure S18. Change in annual mean SIF for 2015 following optimization with SIF relative to SIF prior. 


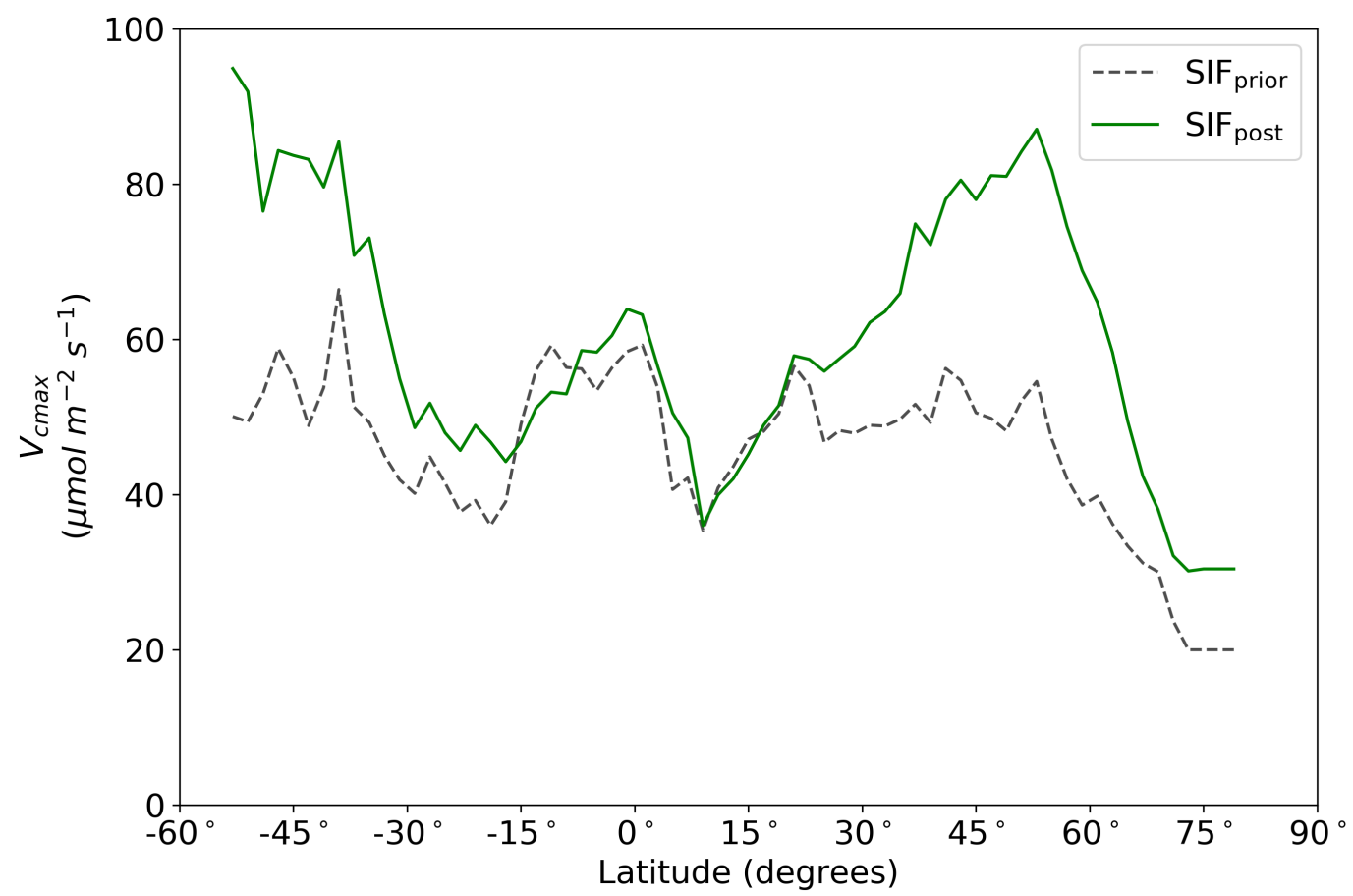

Figure S19. Latitudinal average of mapped maximum carboxylation capacity at $25^{\circ} \mathrm{C}, V_{c m a x}$, parameter values for the prior and posterior cases. 


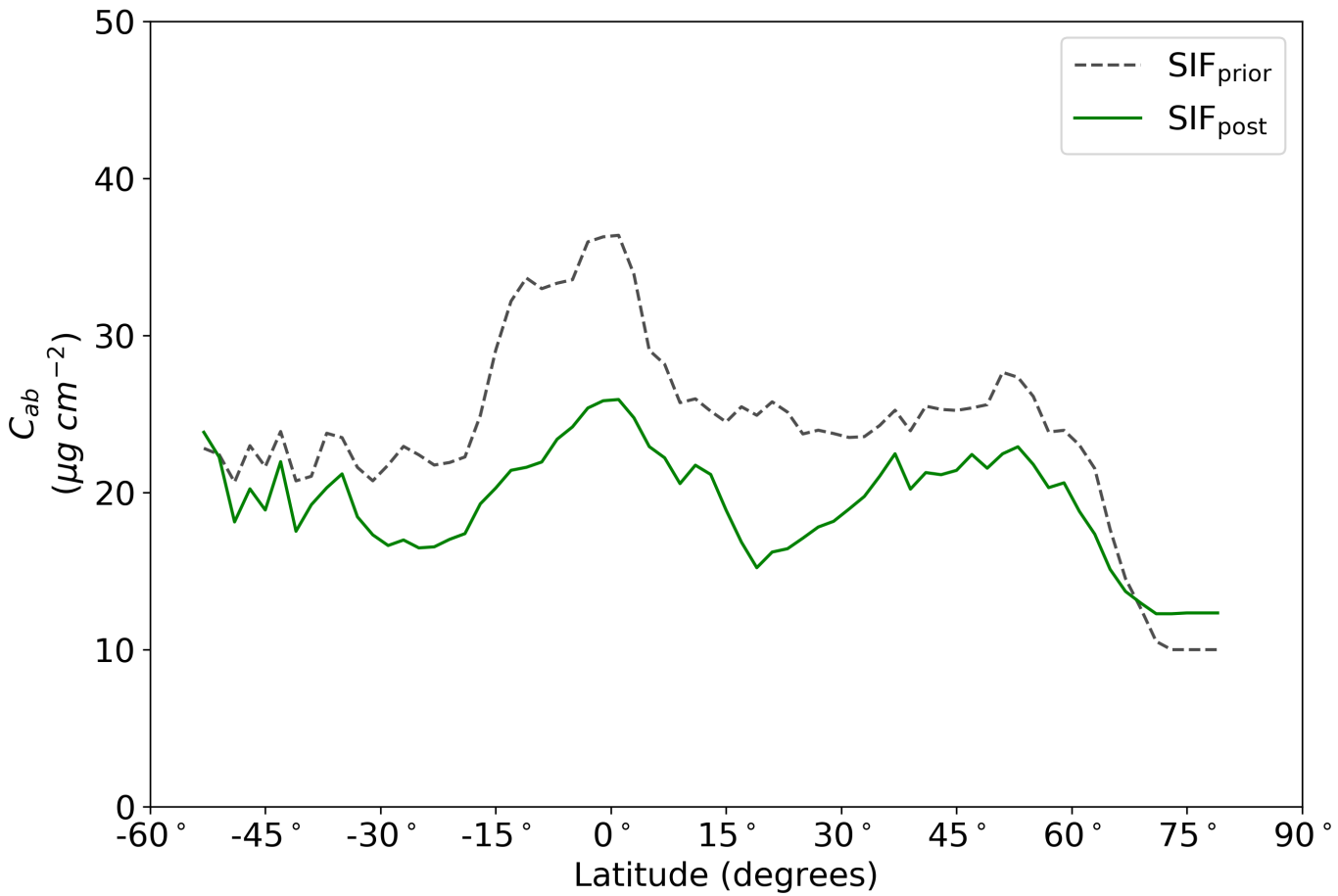

Figure S20. Latitudinal average of mapped chlorophyll content, $C_{a b}$, parameter values for the prior and posterior cases. 